Vol. 21 (2017), pp. 128-149.

ISSNe: 2530-6324 || ISSN: 1138-039X

DOI: https://doi.org/10.17979/afdudc.2017.21.0.3274

\title{
ASPECTOS CONTROVERTIDOS Y PERSPECTIVAS DE EVOLUCIÓN DEL RÉGIMEN JURÍDICO DEL TERCER SECTOR Y EL VOLUNTARIADO
}

\author{
ANDREa GaRRIDO JUNCAL* \\ Profesora contratada interina de Derecho Administrativo \\ Univesidad de Santiago de Compostela
}

\begin{abstract}
Resumen: El presente artículo analiza el régimen jurídico que da cobertura a las actuaciones del tercer sector de acción social y el voluntariado desde el año 2015. El propósito del trabajo es, en primer lugar, encuadrar conceptualmente las organizaciones y personas que se dedican a atender a colectivos con dificultades diversas: discapacitados, infancia, drogodependientes, tercera edad, etc. En segundo lugar, se aclara cuál es la distribución de competencias en materia de asistencia social, pues el nuevo marco regulatorio genera confusión desde esta perspectiva. Las últimas páginas hacen hincapié en algunos asuntos claves que no han sido objeto de atención por parte del legislador estatal, como la reserva de contratos, pero que son fundamentales para fortalecer a estos dos actores destacados en la lucha contra las desigualdades.
\end{abstract}

Palabras clave: tercer sector de acción social, voluntariado, competencias, asistencia social, actividad de fomento.

Abstract: This article analyzes the legal regime that supports the action of the third
sector of social action and the voluntary service since 2015 . The purpose of this article
is, first, to describe in a conceptual way the organizations and persons who deal with
groups with diverse difficulties: disabled persons, infancy, drug addicts, seniors, etc.
Secondly, to clarify the distribution of competences in the area of social assistance, as
the new regulatory framework is a source of confusions in this aspect. The last pages of 
the article focus on some key issues that had not been treated by state legislator, as the reservation of contracts, but are fundamental to strengthen these two actors in the inequalities

prevention.

Keywords: third sector of social action, voluntary service, competences, social assistance, promotion activities

SUMARIO: I. EL NUEVO ENCUADRE CONCEPTUAL DEL VOLUNTARIADO Y EL TERCER SECTOR DE ACCIÓN SOCIAL. II.- LA DISCUTIBLE GARANTÍA DEL RESPETO AL REPARTO DE COMPETENCIAS CONSTITUCIONAL Y ESTATUTARIAMENTE VIGENTE. UN REPASO A LA DOCTRINA CONSTITUCIONAL SOBRE EL ALCANCE DE LA ACTIVIDAD SUBVENCIONAL DEL ESTADO EN EL ÁREA DE LA ASISTENCIA SOCIAL. III.EL FOMENTO DEL TERCER SECTOR DE ACCIÓN SOCIAL Y DEL VOLUNTARIADO A PARTIR DE UNA REFORMA DE LA LEGISLACIÓN DE LA CONTRATACIÓN PÚBLICA. IV.-CONCLUSIONES. V.-BIBLIOGRAFÍA

\section{EL NUEVO ENCUADRE CONCEPTUAL DEL VOLUNTARIADO Y EL TERCER SECTOR DE ACCIÓN SOCIAL}

Antes de adentrarnos en el análisis de la reforma del régimen jurídico del tercer sector de acción social y el voluntariado, es imprescindible dedicar estas líneas iniciales a la delimitación conceptual de estos dos actores.

El art. 2.1 de la Ley 43/2015, de 9 de octubre, del Tercer Sector de Acción Social (en adelante, LTSAS) señala: «son aquellas organizaciones de carácter privado, surgidas de la iniciativa ciudadana o social, bajo diferentes modalidades, que responden a criterios de solidaridad y de participación social, con fines de interés general y ausencia de ánimo de lucro, que impulsan el reconocimiento y el ejercicio de los derechos civiles, así como de los derechos económicos, sociales o culturales de las personas y grupos que sufren condiciones de vulnerabilidad o que se encuentran en riesgo de exclusión social». Puesto que la definición transcrita no determina, de manera precisa y acabada, qué debemos entender exactamente por «tercer sector de acción social», el siguiente apartado de este precepto establece con un ánimo clarificador: «En todo caso, son entidades del tercer sector de acción social las asociaciones, las fundaciones, así como las federaciones o asociaciones que las integren, siempre que cumplan con lo previsto en esta Ley. Para la representación y defensa de sus intereses de una forma más eficaz, y de acuerdo con la Ley Orgánica 1/2002, de 22 de marzo, reguladora del derecho de asociación, y con su normativa específica, las entidades del tercer sector de acción social podrán constituir asociaciones o federaciones que, a su vez, podrán agruparse entre sí». A nuestro parecer, la última observación resulta insuficiente, pues se limita a precisar las figuras jurídicas que puede adoptar el tercer sector de acción social, y sería deseable perfilar con más detalle las funciones que les corresponden a estas organizaciones de carácter privado. A estos efectos, no puede olvidarse que, siguiendo 
un dossier realizado por la Taula d'entitats del Tercer Sector Social de Catalunya, nos encontramos con que los espacios en los que el tercer sector social interviene son nueve: educativo, cultural, deportivo, social, ambiental, sanitario, cooperación, profesional y religioso. En consonancia con ello, queda por resolver cuál es el ámbito de aplicación de este cuerpo legal. Es decir, convendría saber si con las denominaciones «tercer sector social», «tercer sector de acción social» $\mathrm{y}$ «tercer sector» hacemos referencia a la misma realidad o no, pues se usan indistintamente. De hecho, la Ley 39/2006, de 14 de diciembre, de Promoción de la Autonomía Personal y Atención a las personas en situación de dependencia, prefiere referirse al tercer sector y proporciona otra posible definición: «las organizaciones de carácter privado surgidas de la iniciativa ciudadana o social, bajo diferentes modalidades que responden a criterios de solidaridad, con fines de interés general y ausencia de ánimo de lucro, que impulsan el reconocimiento y el ejercicio de los derechos sociales» (art. 2).

El tercer sector es una figura subjetiva difícil de identificar, determinar y valorar por su extraordinaria heterogeneidad, la cual se manifiesta en las denominaciones, los enfoques conceptuales, las formas jurídicas y las dimensiones que revisten estas instituciones.

En relación con la expresión, es preciso apuntar que se sustituye en ocasiones por otras locuciones como «organizaciones no gubernamentales», «sector no lucrativo», «sector privado social», «entidades sin ánimo de lucro», «organizaciones sociales» o «sector non profit» Dichas denominaciones resaltan algunas de las características más representativas de estas organizaciones. En unos casos, subrayan sus rasgos positivos («organizaciones voluntarias») $\mathrm{y}$, en otros, destacan sus diferencias respecto del gobierno («organizaciones no gubernamentales», «sector voluntario», «sector público no estatal») o del sector empresarial («sector no lucrativo», «economía social») ${ }^{1}$.

En el mundo anglosajón, donde primero se desarrollaron estas entidades, el fenómeno se conoce como «sector non profit»; en el modelo continental europeo, y preferentemente en el latino, se utiliza más la expresión «tercer sector». Marcos VAQUER CABALLERÍA incide en que «tal diferencia terminológica no puede atribuirse a la casualidad, si se tiene presente que en los países anglosajones los poderes públicos tienen una larga tradición de confianza a agentes sociales de la prestación de los servicios a la persona (educación, sanidad, cultura), cuya titularidad se les reconoce y acompaña de la financiación y vigilancia que demandan el interés general; mientras que los países continentales han tratado de desarrollar más bien su Estado social sobre la base de la tradicional separación entre lo público y lo privado, mediante la publificación y gestión directa de ciertos servicios esenciales» ${ }^{2}$.

En la compresión del tercer sector existen principalmente dos enfoques conceptuales tradicionalmente en pugna. Desde la tradición europea continental, lo importante es la dimensión democrática de las organizaciones y la producción para el mercado de bienes sociales. Desde la tradición anglosajona, se destaca la importancia de la no distribución de beneficios por parte de las entidades, así como la presencia del voluntariado. Con el propósito de superar esta división de enfoques, se han realizado esfuerzos por concretar una delimitación conceptual del tercer sector en la que confluyan las dos tradiciones y el

\footnotetext{
${ }^{1}$ Véase José Luis IZQUIETA ETULIAN, Voluntariado y tercer sector. Cultura, participación cívica y organizaciones solidarias, Tecnos, Madrid, 2011, págs. 17-18.

${ }^{2}$ Véase "Las relaciones entre Administración pública y tercer sector, a propósito de la asistencia social en Italia", Revista de Administración Pública, núm. 152, mayo-agosto 2000, http.//revistaonline.inap.es.
} 
resultado ha sido la siguiente definición: «es el ámbito formado por entidades privadas de carácter voluntario y sin ánimo de lucro que, surgidas de la libre iniciativa ciudadana, funcionan de forma autónoma y solidaria tratando por medio de acciones de interés general, de impulsar el reconocimiento y el ejercicio de los derechos sociales, de lograr la cohesión y la inclusión social en todas sus dimensiones y de evitar que determinados colectivos sociales queden excluidos de unos niveles suficientes de bienestar» ${ }^{3}$.

Las formas jurídicas que revisten las entidades que engloban el tercer sector son muy variadas, si bien la mayoría de ellas pivota sobre la base de la clasificación fundamental que distingue entre personas jurídicas de base asociativa y personas jurídicas de base fundacional. Piénsese, por ejemplo, como particularmente representativas de nuestro país, en Cáritas, de carácter asociativo, o en la Organización Nacional de Ciegos Españoles, de carácter fundacional. A ellas se añaden, con menor importancia cuantitativa, las sociedades cooperativas y las mutualidades de previsión social o «entidades aseguradoras privadas sin ánimo de lucro que ejercen una modalidad aseguradora de carácter voluntario complementaria al sistema de Seguridad Social obligatoria, mediante aportaciones a prima fija o variable de los mutualistas, personas físicas o jurídicas, o de otras entidades o personas protectoras» (art. 2.1 del RD 1430/2002, de 27 de diciembre, por el que se aprueba el Reglamento de mutualidades de previsión social) ${ }^{4}$.

En suma, la diversidad del tercer sector se refiere a sus denominaciones, a sus definiciones, a su grado de formalización jurídica, pero también a su dimensión. Tal y como advierte Santiago MUÑOZ MACHADO, tenemos instituciones no lucrativas con muchos recursos y capacidad de gestión y otras que apenas pueden desarrollar autónomamente programas que merezcan reconocerse ${ }^{5}$. No obstante, debido a que se caracteriza fundamentalmente por una gran base de pequeñas entidades que cuentan con una sola sede y están presentes generalmente en un único ámbito geográfico, es posible sentenciar que el tercer sector constituye un conjunto de entidades, además de diverso, disperso.

De conformidad con la Ley 45/2015, de 14 de octubre, de Voluntariado (en adelante, LV), el voluntariado se define como: «el conjunto de actividades de interés general desarrolladas por personas físicas, siempre que reúnan los siguientes requisitos:

a) Que tengan carácter solidario.

b) Que su realización sea libre, sin que tengan su causa en una obligación personal o deber jurídico y sea asumida voluntariamente.

\footnotetext{
${ }^{3}$ Véase Anuario del Tercer Sector de Acción Social en España, Fundación Luis Vives, Madrid, 2012. págs. 9-13.

4 La mejor muestra de que la forma jurídica que adoptan los entes integrantes del tercer sector adopta denominaciones externas que permiten su encuadre en tipos diversos de personas jurídicas lo constituye el caso de las ONGs: pueden adoptar forma jurídica de carácter asociativo o fundacional, pues el concepto de ONG es de tipo sociológico, no jurídico, y, por tanto, puede derivar en distintas formas jurídicas siempre que cumplan con el requisito de no depender directa ni indirectamente de un ente gubernamental. Véase Marta PÉREZ ESCOLAR y Jesús Alberto VALERO MATAS, Entes sin ánimo de lucro. Fundamentos sociológicos. (Manual teórico-práctico adaptado EEES), Tecnos, Madrid, 2013, págs.135-137.

5 Véase "La contribución de las organizaciones sociales a la transformación del Estado de Bienestar", Las estructuras del bienestar. Propuestas de reformas y nuevos horizontes, Civitas, Madrid, 2002, pág. 715 .
} 
c) Que se lleven a cabo sin contraprestación económica o material, sin perjuicio del abono de los gastos reembolsables que el desempeño de la acción voluntaria ocasione a los voluntarios de acuerdo con lo establecido en el artículo 12.2.d).

d) Que se desarrollen a través de entidades de voluntariado con arreglo a programas concretos y dentro o fuera del territorio español sin perjuicio de lo dispuesto en los artículos 21 y 22».

La delimitación conceptual del voluntariado recogida en el art. 3.1 de la LV se complementa con otras tres aclaraciones. La primera, consistente en identificar las actividades de interés general ${ }^{6}$. La segunda, que pasa por exponer que determinadas

\footnotetext{
${ }^{6}$ En concreto, el art.3.2 de la LV dispone: «se entiende por actividades de interés general, aquellas que contribuyan en cada uno de los ámbitos de actuación del voluntariado a que hace referencia el artículo 6 a mejorar la calidad de vida de las personas y de la sociedad en general y a proteger y conservar el entorno». El artículo al que se refiere este precepto declara:

«1. Se consideran ámbitos de actuación del voluntariado, entre otros, los siguientes:

a) Voluntariado social, que se desarrolla mediante la intervención con las personas y la realidad social, frente a situaciones de vulneración, privación o falta de derechos u oportunidades para alcanzar una mejor calidad de vida y una mayor cohesión y justicia social.

b) Voluntariado internacional de cooperación para desarrollo, vinculado tanto a la educación para el desarrollo como parte del proceso educativo y de transformación, como a la promoción para el desarrollo en lo relativo a la acción humanitaria y la solidaridad internacional, ya se realice en nuestro país, en países o territorios receptores de cooperación al desarrollo o en cualquier país donde se declare una situación de necesidad humanitaria, sin perjuicio de las actividades realizadas en este ámbito por los cooperantes, que se regirán por el Real Decreto 519/2006, de 28 de abril, por el que se establece el Estatuto de los cooperantes.

c) Voluntariado ambiental, que persigue disminuir el impacto negativo del ser humano sobre el medio ambiente y poner en valor el patrimonio natural existente, las especies animales y vegetales, los ecosistemas y los recursos naturales realizando, entre otras, acciones de protección y recuperación de la flora y fauna, la biodiversidad natural de los distintos hábitats, y defensa del medio forestal; de conservación y mejora del agua, de los ríos y otros elementos del medio hídrico; del litoral, de las montañas y demás elementos del paisaje natural; de educación y sensibilización medioambiental; de protección de los animales; y cualesquiera otras que contribuyan a proteger, conservar y mejorar el medio
} ambiente.

d) Voluntariado cultural, que promueve y defiende el derecho de acceso a la cultura y, en particular, la integración cultural de todas las personas, la promoción y protección de la identidad cultural, la defensa y salvaguarda del patrimonio cultural y la participación en la vida cultural de la comunidad.

e) Voluntariado deportivo, que contribuye a la cohesión ciudadana y social, sumando los valores propios del voluntariado con aquellos otros inherentes al deporte, apostando decididamente por fomentar la dimensión comunitaria en el desarrollo de la práctica deportiva en cualquiera de sus manifestaciones, incluido el voluntariado en deporte practicado por personas con discapacidad, con particular atención al paralímpico, y por favorecer un mayor y decidido compromiso de quienes practican deporte en la vida asociativa, como manera eficaz de promover su educación e inclusión social.

f) Voluntariado educativo, que como acción solidaria planificada e integrada en el sistema y la comunidad educativa mejore las posibilidades de realización de actividades extraescolares y complementarias contribuyendo, en particular, a compensar las desigualdades que pudieran existir entre los alumnos por diferencias sociales, personales o económicas, mediante la utilización, entre otros, de programas de aprendizaje-servicio.

g) Voluntariado socio-sanitario en el que se combinan, la promoción de la salud, la prevención de la enfermedad, la asistencia sanitaria, la rehabilitación y la atención social que va dirigida al conjunto de la sociedad o a los colectivos en situación de vulnerabilidad, y que, mediante una intervención integral y especializada en los aspectos físico, psicológico y social, ofrece apoyo y orientación a las familias y al entorno más cercano, mejorando las condiciones de vida.

h) Voluntariado de ocio y tiempo libre, que forma y sensibiliza en los principios y valores de la acción voluntaria mediante el desarrollo de actividades en el ámbito de la educación no formal, que fomenten el desarrollo, crecimiento personal y grupal de forma integral, impulsando habilidades, competencias, aptitudes y actitudes en las personas, que favorezcan la solidaridad y la inclusión, y logren el compromiso, la participación y la implicación social. 
acciones no tienen la consideración de voluntariado ${ }^{7}$. Y la tercera, que tiene como objetivo, según la Exposición de motivos, reconocer las nuevas formas de voluntariado que han emergido con fuerza en los últimos años. Estas son las que se traducen en la realización de acciones concretas y por un lapso de tiempo explícito, sin integrarse en programas globales o a largo plazo o las que se llevan a cabo por voluntarios a través de las tecnologías de la información y comunicación y que no requieren la presencia física de los voluntarios en las entidades de voluntariado. Respecto de esta previsión, es necesario poner de manifiesto que parece que el legislador se hace eco de las actividades denominadas comúnmente como crowdfunding. De todos modos, la regulación del tema es muy escueta y no se abordan los problemas de enjundia jurídica que plantea esta alternativa al mecanismo de financiación tradicional. En particular, la Ley no se inmiscuye en la ardua tarea de dotar de mayor seguridad a los "inversores".

El art. 3 de la Ley 1/2015, de 24 de febrero, del Voluntariado en la Comunidad de Madrid dispone: «A los efectos de la presente ley, se entiende por voluntariado el conjunto de actividades de interés general desarrolladas por personas físicas en el seno de organizaciones públicas o privadas, que tengan un carácter libre, gratuito y solidario, sin que tengan por causa una obligación personal o un deber jurídico». La Ley 25/2015, de 30 de julio, del Voluntariado y Asociacionismo de Cataluña recoge, en el art. 3, las definiciones de voluntariado ${ }^{8}$, voluntarios ${ }^{9}$, acción voluntaria ${ }^{10}$, asociacionismo $^{11}$,

i) Voluntariado comunitario, que favorece la mejora de la comunidad, y promueve la participación con mayor poder de decisión e iniciativa para resolver los problemas y exigir mayor calidad de vida en los espacios vitales más cercanos donde se desenvuelven los voluntarios, vertebrando una sociedad solidaria, activa, crítica, comprometida y corresponsable.

j) Voluntariado de protección civil, que colabora regularmente en la gestión de las emergencias, en las actuaciones que se determinen por el Sistema Nacional de Protección Civil sin perjuicio del deber de los ciudadanos en los casos de grave riesgo, catástrofe o calamidad pública, como expresión y medio eficaz de participación ciudadana en la respuesta social a estos fenómenos, en los términos que establezcan las normas aplicables.

2. Reglamentariamente se regularán las condiciones en las que se llevará a cabo las actividades de voluntariado internacional de cooperación para el desarrollo, así como en aquellos otros ámbitos de actuación que, bien por el lugar en que se realizan, bien por la especialidad de las actividades, bien por el tiempo de desarrollo de éstas o por la combinación de algunas de las circunstancias anteriores, requieren de un tratamiento diferenciado».

${ }^{7} \mathrm{El}$ art. 3.3 de la LV indica: «No tendrán la consideración de actividades de voluntariado las siguientes:

a) Las aisladas o esporádicas, periódicas o no, prestadas al margen de entidades de voluntariado.

b) Las ejecutadas por razones familiares, de amistad o de buena vecindad.

c) Las que se realicen en virtud de una relación laboral, funcionarial, mercantil o de cualquier otra mediante contraprestación de orden económico o material.

d) Los trabajos de colaboración social a los que se refiere el Real Decreto 1445/1982, de 25 de junio, por el que se regulan diversas medidas de fomento del empleo.

e) Las becas con o sin prestación de servicios o cualquier otra actividad análoga cuyo objetivo principal sea la formación.

f) Las prácticas no laborales en empresas o grupos empresariales y las prácticas académicas externas».

${ }^{8}$ «El conjunto de acciones y actividades de interés general motivadas por el altruismo y la voluntad de transformación social que cumplen personas físicas, denominadas voluntarios, que participan en proyectos en el marco de una actividad asociativa o bien en programas específicos de voluntariado de una entidad sin ánimo de lucro, de acuerdo con lo establecido por la presente ley».

9 «Las personas físicas que, de una forma libre, sin contraprestación económica y de acuerdo con la capacidad de obrar que les reconoce el ordenamiento jurídico, deciden dedicar parte de su tiempo al servicio de los demás o a intereses sociales y colectivos mediante la participación en programas de voluntariado que llevan a cabo entidades sin ánimo de lucro -con las que formalizan un compromiso que origina los derechos y deberes que regula la presente ley- o bien mediante el asociacionismo y la participación en los distintos proyectos que puedan llevarse a cabo en este marco». 
entidad de voluntariado ${ }^{12}$, destinatarios de la acción voluntaria ${ }^{13}$ y programa de voluntariado $^{14}$. Si hemos optado por la reproducción textual en las notas al pie de página de los precedentes conceptos ha sido porque su tenor literal es la mejor prueba de que los legisladores autonómicos se han decantado, al igual que el legislador estatal, por grandilocuentes proclamaciones legales que carecen de toda relevancia, tanto práctica como dogmática.

De cuanto antecede, se deduce que las nociones «tercer sector acción social» y «Voluntariado» constituyen el punto de partida de la LTSAS y la LV. Dada la espontaneidad, riqueza y diversidad de los movimientos de participación ciudadana en la vida pública, en los que destaca como elemento esencial la libertad, se aboga quizá por una forma de legislar abierta, creyendo que esa técnica es más respetuosa con ese valor. De todas formas, debido a que en estos momentos se debaten las fronteras entre lo público y lo privado, el Consejo Económico y Social entiende que debería mejorarse la redacción referente a la definición de los límites de la actuación del tercer sector de la acción social y del voluntariado en relación con las obligaciones de los poderes públicos. Por ello, desde la óptica de este órgano, sería aconsejable perfilar con más claridad los papeles que corresponden a cada uno, con el objetivo de que la promoción de las entidades privadas sin ánimo de lucro o del voluntariado se realice sin menoscabo de las funciones que corresponden a las Administraciones en el ámbito social, esto es, prevaleciendo siempre el principio de no sustitución de los servicios públicos.

En un segundo orden de cosas, el Consejo Económico y Social observa que el texto aplicable al tercer sector de acción social resulta, en algunos aspectos, demasiado generalista y programático, pudiendo generar incluso inseguridad jurídica al no definir con suficiente claridad conceptos utilizados en la Ley como el de interés general ${ }^{15}$,

10 «La acción llevada a cabo por una persona que, libre y solidariamente, por propia voluntad y sin compensación económica, decide dedicar parte de su tiempo a ejercer, de forma compartida con otras personas, un compromiso de transformación de la sociedad, en el marco de una actividad asociativa, en un programa específico de voluntariado de una entidad sin ánimo de lucro y en beneficio de terceros»

11 «La actividad de implicación social sin ánimo de lucro ni personal ni colectivo, basada en la participación colectiva y comprometida, la autoorganización, el voluntariado, la gestión democrática y la voluntad de transformación social o personal».

12 «La entidad privada sin ánimo de lucro que cumple actividades de interés general, que ha decidido que la participación voluntaria de los ciudadanos es un valor imprescindible en su misión para lograr sus fines y que ha elaborado un programa de voluntariado que define y enmarca el valor y los espacios de la acción voluntaria en la entidad. Dicho programa es potestativo para las entidades de base asociativa».

13 «Las personas físicas, consideradas individualmente o integradas en grupos, para las que la acción voluntaria supone un beneficio, la defensa de sus derechos, la mejora de las condiciones de vida o la satisfacción de sus necesidades».

${ }^{14}$ «El documento formal, aprobado por el órgano de gobierno de una entidad de voluntariado, que recoge sistematizada y justificadamente la voluntad de la entidad de organizar una o más actividades de interés general que complementen el cumplimiento de sus objetivos o coadyuven a ello, con la participación de voluntarios como valor añadido de la organización».

${ }^{15}$ Respecto a este interés general y, en particular, a aquel al que deben servir las fundaciones, José Luis PIÑAR MAÑAS declara: «es el interés superior al individual, incluso al de grupo si éste está integrado por sujetos no genéricamente individualizados. Pero ese interés general puede llegar a ser el mismo al que deben servir las Administraciones Públicas. Ningún límite se ha establecido al respecto ni en la Constitución ni en la Ley de Fundaciones. En consecuencia, para que el derecho de fundación resulte constitucionalmente garantizado, las fundaciones deben perseguir (y por tanto los fundadores establecer) un interés superior al individual, que puede llegar a ser el mismo interés general a que se refiere el artículo 103. Incluso nada impediría que ese interés general fuese considerado interés nacional por el fundador. Pero en este caso, debe estimarse que la definición que haga el fundador no tiene mayor alcance que el de autodefinirse como tal. Así como no hay un monopolio del legislador en definir qué se entiende 
expresión que por cierto la doctrina y la jurisprudencia no siempre distinguen del interés público $^{16}$. En cambio, en otros, se excede en el detalle, como ocurre con la definición de los principios rectores. Respecto del texto que atañe al voluntariado, cabe anotar que la precepción del Consejo Económico y Social no difiere. En su opinión, no se resuelven satisfactoriamente las relaciones entre empleo y voluntariado, de modo que varios artículos inducen a confusión respecto a la naturaleza de determinadas situaciones de prestación de servicios. Si bien el estilo de redacción no contribuye a diferenciar con nitidez las dos anteriores situaciones, se resalta igualmente que, a veces, con el propósito de intentar abarcar todas las tipologías y dimensiones posibles del voluntariado, la norma se excede en el desarrollo de determinados contenidos, alcanzando una exhaustividad más propia de un reglamento que de una Ley. Es el caso del apartado 1 del art. 6, donde se tratan de acotar los ámbitos de actuación del voluntariado sin lograr una clara definición de los mismos y, además, pudiendo limitar el desarrollo reglamentario específico que contempla el apartado 4 de dicho artículo. Lo mismo ocurre en el art. 8 sobre programas de voluntariado, pues el contenido mínimo de estos programas debería ser objeto de una reglamentación posterior ${ }^{17}$.

En línea con lo expuesto y lo expresado por el Consejo Económico y Social, podemos concluir, de manera preliminar, que el hecho de que las definiciones de «tercer sector de acción social»y «voluntariado» estén plagadas de inconcreciones no es positivo. Al pasar las Leyes de puntillas por esta cuestión, son muchos los problemas que se generan, pero nos limitaremos a exponer uno. El primero, este panorama favorece a la perpetuación de un fallo muy grave, detectado en el Resumen Ejecutivo del Tercer Sector de Acción Social en 2015: Impacto de la crisis, que es el desconocimiento o la incomprensión de esta parte del ordenamiento jurídico ${ }^{18}$. Desde nuestro punto de vista, es pertinente resaltar que se establecen dos regímenes jurídicos distintos, uno para las entidades de voluntariado ${ }^{19}$ y otro para el tercer sector de acción social, desconociendo el deslinde entre uno y otro, y con una consecuencia importantísima. La LTSAC no

por interés general, sí lo hay para definir qué se entiende por interés nacional». ("El estado actual del modelo constitucional de fundaciones: revisión crítica", Nuevo Tratado de Fundaciones, Rafael de LORENZO GARCÍA, José Luis PIÑAR MAÑAS y Isabel PEÑALOSA ESTEBAN (dirs.), Aranzadi, Madrid, pág. 79)

${ }^{16}$ Véase Xaime RODRÍGUEZ-ARANA MUÑOZ, "El interés general en el Derecho Administrativo: notas introductorias", Revista Jurídica de Canarias, núm. 24, 2012, págs. 41-54.

${ }^{17}$ Consúltese el Dictamen 1/2015 sobre el Anteproyecto de Ley de Voluntariado y el Dictamen 2/2015 sobre el Anteproyecto de Ley del Tercer Sector de Acción Social, aprobados en sesión ordinaria del pleno 25 de febrero de 2015.

${ }^{18}$ El trabajo de investigación ha sido realizado por Systeme Innovación y Consultoría, véase pág. 29.

${ }^{19} \mathrm{El}$ art. 13 de la LV declara:

«1. Tendrán la consideración de entidades de voluntariado las personas jurídicas que cumplan los siguientes requisitos:

a) Estar legalmente constituidas e inscritas en los Registros competentes, de acuerdo con la normativa estatal, autonómica o de otro Estado miembro de la Unión Europea de aplicación.

b) Carecer de ánimo de lucro.

c) Estar integradas o contar con voluntarios, sin perjuicio del personal de estructura asalariado necesario para el funcionamiento estable de la entidad o para el desarrollo de actuaciones que requieran un grado de especialización concreto.

d) Desarrollar parte o la totalidad de sus actuaciones mediante programas de voluntariado diseñados y gestionados en el marco de las actividades de interés general, que respeten los valores, principios y dimensiones establecidos en el artículo 5 y se ejecuten en alguno de los ámbitos recogidos en el artículo 6.

2. En todo caso tendrán la consideración de entidades de voluntariado las federaciones, confederaciones o uniones de entidades de voluntariado legalmente constituidas en el ámbito estatal o autonómico o de la Unión Europea». 
reconoce explícitamente ningún derecho ni tampoco ningún deber a nadie, ni a las personas que conforman el tercer sector de acción social ni a los destinatarios de sus acciones.

Tras estas reflexiones previas, que son el punto de arranque del presente estudio, estimamos conveniente añadir que el 20 de mayo de 2016 entraba en vigor la Ley 6/2016, de 12 mayo, del Tercer Sector Social de Euskadi ${ }^{20}$ Así pues, no podemos finalizar este primer apartado sin apuntar que es previsible que los restantes legisladores autonómicos no descarten aprobar su propia ley en un futuro próximo. En nuestra opinión, las propuestas gubernamentales de este tipo tienen prima facie una lectura positiva al mismo tiempo que oportunista. De hecho, así lo ha exteriorizado el Consejo Económico y Social Vasco, en su dictamen 15/14 sobre el Anteproyecto de Ley del Tercer Sector Social de Euskadi, al afirmar que «se supone que el tercer sector es un activo a considerar en cualquier tipo de coyuntura no sólo en la de crisis, sino también en las más favorables, donde su intervención de carácter complementario está llamada a contribuir al "desarrollo" de las potencialidades de la sociedad. Más aún, esa apelación a la circunstancia coyuntural de la crisis para subrayar la razón de ser del tercer sector, cuando la presencia y actividad de éste viene siendo muy anterior a la coyuntura actual, resulta "oportunista" y pudiera dar a entender que, a través de él, se pretende suplir y paliar las carencias y recortes de la intervención y aportación que corresponde hacer a los poderes públicos». En concordancia con lo anterior, resaltamos que la entrada en vigor de la LTSAS y la LV son un hecho inédito en el ordenamiento jurídico español. España es el sexto país de la Unión Europea en participación de voluntarios. Nuestro país cuenta con alrededor de seis millones de voluntarios, un 15 por 100 de la población, y con unas treinta mil entidades sociales, cuya actividad representa casi un 2 por 100 del PIB y da empleo a prácticamente 63.6000 personas. Datos como éstos ilustran la importancia de las citadas normas, que vienen además a reforzar la capacidad de interlocución de dichos sujetos con la Administración. Ahora bien, importa subrayar que el leitmotiv, en ningún caso, puede ser diluir las responsabilidades de la última.

\section{LA DISCUTIBLE GARANTÍA DEL RESPETO AL REPARTO DE COMPETENCIAS CONSTITUCIONAL Y ESTATUTARIAMENTE VIGENTE. UN REPASO A LA DOCTRINA CONSTITUCIONAL SOBRE EL ALCANCE DE LA ACTIVIDAD SUBVENCIONAL DEL ESTADO EN EL ÁREA DE LA ASISTENCIA SOCIAL}

\footnotetext{
${ }^{20}$ Según esta Ley, el tercer sector social de Euskadi está conformado por el conjunto de organizaciones, con estructura legal y personalidad jurídica, inscritas en el registro correspondiente a su figura jurídica, de acción voluntaria, no lucrativas, privadas, autogobernadas y autogestionadas, con sede y actividad en Euskadi, cuya finalidad principal es promover la inclusión social, la cooperación al desarrollo y el ejercicio efectivo de los derechos de las personas, familias, colectivos o comunidades que afrontan situaciones de vulnerabilidad o exclusión, desprotección y dependencia, a través de actividades de intervención social, entendiendo por tales los servicios sociales, la promoción del acceso al empleo y cualquier otra orientada a promover la inclusión social de aquellas, incluidas las actividades desarrolladas con esta finalidad en los espacios de interacción entre ámbitos, políticas y sistemas, como los espacios sociolaboral, sociohabitacional, socioeducativo, sociosanitario, sociojudicial o sociocultural, u otros. Por tanto, el tercer sector social incluye el tercer sector de acción social o el ámbito de los servicios sociales o de la acción social en sentido estricto, pero lo desborda, abarcando también otros ámbitos encuadrados en las políticas sociales en sentido amplio, como el empleo o el sistema de garantía de ingresos y para la inclusión social.
} 
El tenor literal de la Disposición adicional primera de la LTSAS pone de manifiesto que este texto legal «se aplicará, sin perjuicio de las competencias atribuidas a las Comunidades Autónomas en materia de asistencia social por sus Estatutos de Autonomía, así como en su legislación específica». Por otra parte, la Disposición final segunda de la LTSAS explica que «esta Ley se dicta al amparo del artículo 149.1.1. ${ }^{a}$ de la Constitución que atribuye al Estado la competencia exclusiva sobre la regulación de las condiciones básicas que garanticen la igualdad de todos los españoles en el ejercicio de los derechos y en el cumplimiento de los deberes constitucionales, excepto el segundo párrafo de la Disposición adicional segunda que se dicta al amparo de lo dispuesto en el artículo 149.1.31. a de la Constitución que atribuye al Estado la competencia en materia de Estadística para fines estatales». El respeto al ámbito competencial de las Comunidades Autónomas se declara igualmente en la LV (Disposición final segunda) y el título competencial bajo el que el legislador estatal aprueba esa norma es el mismo (Disposición final cuarta).

Para poder cumplir el objetivo de no alterar el sistema de reparto competencial, de un lado, y de reforzar el papel del tercer sector de acción social y el voluntariado, de otro, parece prudente examinar la jurisprudencia del Tribunal Constitucional en materia de asistencia social y, en concreto, aquella relativa a la actividad subvencional del Estado en este segmento de la acción pública. De hecho, así se ha recomendado en la Resolución 1846/2016, de 18 de julio, que hace público un acuerdo de la Subcomisión de Seguimiento Normativo, Prevención y Solución de Conflictos de la Comisión Bilateral Generalidad-Estado en relación con la LTSAC $^{21}$ y en la Resolución 1847/2016, de 18 de julio, por la que se hace público otro acuerdo de la Subcomisión de Seguimiento Normativo, Prevención y Solución de Conflictos de la Comisión Bilateral Generalidad-Estado en relación con la $\mathrm{LV}^{22}$.

Debemos comenzar recordando que, de acuerdo con el FJ 3 de la STC 138/2009, de 15 de junio, la resolución de aquellas discrepancias que se susciten respecto a la regulación y aplicación de las ayudas o subvenciones que puedan establecerse en las distintas áreas de la acción pública ha de tener en cuenta la distribución de competencias existente en la materia en la que proceda encuadrar las ayudas o subvenciones de que se trate.

La Constitución se refiere, en el art. 148.1.20, a la asistencia social como una materia sobre la que las Comunidades Autónomas pueden asumir competencias. Según el Tribunal Constitucional, «atendiendo a las pautas de algunos instrumentos internacionales como la Carta social europea, la asistencia social, en sentido abstracto, abarca a una técnica de protección situada extramuros del sistema de la Seguridad Social, con caracteres propios, que la separan de otras afines o próximas a ella. Se trata de un mecanismo protector de situaciones de necesidad específicas, sentidas por grupos de población a los que no alcanza el sistema de Seguridad Social y que opera mediante técnicas distintas de las propias de ésta. Entre sus caracteres típicos se encuentran, de una parte, su sostenimiento al margen de toda obligación contributiva o previa colaboración económica de los destinatarios o beneficiarios y, de otra, su dispensación por entes públicos o por organismos dependientes de entes públicos, cualesquiera que éstos sean. De esta forma, la asistencia social vendría conformada como una técnica pública de protección, lo que la distingue de la clásica beneficencia, en la que

\footnotetext{
${ }^{21}$ Han sido objeto de discrepancia los arts. 6 y 7 y las Disposiciones adicional sexta y transitoria única.

${ }^{22}$ Se suscitaron discrepancias en relación con los arts. 2, 17.1, 18.1.a), d) y g); y 20.1.
} 
históricamente halla sus raíces» (SSTC 36/2012, de 15 de marzo, FJ 4, y 21/2013, de 31 de enero, FJ 4) ${ }^{23}$.

Si bien todos los Estatutos de Autonomía han declarado la asistencia social como una competencia autonómica exclusiva, es necesario advertir que ello no cierra el paso a las competencias estatales previstas en el art. 149.1 de la CE, no precisándose en modo alguno expresa salvaguarda de las mismas puesto que constituyen límites infranqueables a los enunciados estatutarios (STC 31/2010, de 28 de junio, FFJ 59 y 64). Aunque la Comunidad Autónoma tenga competencia exclusiva en esta materia, ello no significa, ni impide, el ejercicio de las competencias propias del Estado cuando dichas competencias «concurran con las autonómicas sobre el mismo espacio físico o sobre el mismo objeto jurídico» (STC 31/2010, de 28 de junio). Quiere esto decir que, aunque estemos ante competencias autonómicas sobre materias no incluidas en el art. 149.1 de la CE y denominadas como competencias exclusivas, ello no frena el ejercicio de las competencias estatales que se relacionan en el citado art. 149.1. Por ejemplo, la asistencia social, como competencia autonómica exclusiva, no afecta a la competencia estatal que atañe a las relaciones internacionales (art. 149.1.3 de la CE), cuando se trata de programas internacionales de ayuda [STC 13/1992, de 6 de febrero, FJ 13, K), a)]. En coherencia con lo anterior, comprobamos que el Estado ha alegado también las competencias sobre la regulación de las condiciones básicas que garanticen la igualdad de todos los españoles en el ejercicio de los derechos (art. 149.1.1 de la CE), sobre inmigración (art. 149.1.2 de la CE), sobre hacienda general y deuda del Estado (art. 149.1.14 de la CE) y sobre las bases del régimen jurídico de las Administraciones públicas (art. 149.1.18 de la CE) para convocar ayudas en esta parcela de la actividad administrativa $^{24}$.

\footnotetext{
${ }^{23}$ La distinción de la Seguridad Social respecto de la asistencia social ha generado importantes debates y conflictos; especialmente, desde que la Seguridad Social deja de estar limitada a las prestaciones contributivas. Interesa remarcar que un criterio de diferenciación posible sería el que se atuviera al tipo de prestaciones, es decir, las prestaciones económicas, contributivas y no contributivas, forman parte de la Seguridad Social, mientras que las prestaciones técnicas serían propias de la asistencia social. Sin embargo, este criterio no responde a la realidad, ya que el Estado lleva a cabo prestaciones técnicas y las Comunidades Autónomas incluyen las prestaciones económicas dentro de la asistencia social. (Joaquín TORNOS MAS, "Significación y consecuencias jurídicas de la consideración de los servicios sociales como servicio público”, Cuadernos de Derecho Local, núm. 6, 2004, págs. 5-6).

Al delimitar el ámbito subjetivo de la protección de la asistencia social, no podemos decir que los destinatarios son aquellos grupos de población a los que no alcanza el mecanismo protector de situaciones de necesidades articulado como Seguridad Social. Los beneficiarios de las prestaciones de la Seguridad Social pueden disfrutar también de las prestaciones de la asistencia social dispensadas por una Comunidad Autónoma. La propia STC 239/2002, 11 de diciembre, puntualiza que, si bien la inclusión subjetiva en la Seguridad Social es un elemento a tener en cuenta a la hora de determinar la naturaleza jurídica de una prestación social otorgada por una Comunidad Autónoma, no puede considerarse determinante a efectos de la delimitación competencial por dos motivos fundamentales. De una parte, porque la experiencia demuestra la compatibilidad de medidas de asistencia social con otras correspondientes al sistema de Seguridad Social. Y, de otra, aparentemente más importante, porque la hasta ahora tendencia hacia la universalización de la acción protectora de la Seguridad Social supondría un correlativo vaciamiento de competencias autonómicas. Además, conviene objetar la visión de la asistencia social como una técnica pública de protección caracterizada por una carente colaboración económica por parte del destinatario. Tras la crisis económica, la búsqueda de líneas de financiación ha llevado a plantear el tema del copago por el usuario que recibe este servicio y, en consecuencia, la distinción entre las prestaciones en cuyo pago tienen que participar las personas usuarias y las prestaciones en que no.

${ }^{24}$ Conviene anotar que, si bien todos los Estatutos de Autonomía han declarado los servicios sociales (o la asistencia social) como una competencia autonómica exclusiva, los conflictos competenciales entre las Comunidades Autónomas y el Estado han sido bastante frecuentes en los últimos tiempos. A raíz de la
} 
Debido a la obligatoria limitada extensión del presente estudio, nos detendremos únicamente en la interpretación de la competencia reconocida al Estado en el art. 149.1.1 de la CE. A través del mencionado título competencial, es posible promover mandatos, no ya genéricos sino específicos, recogidos en la Constitución como son los establecidos en el art. 50, en relación con las personas mayores, o en el art. 49, en relación con las personas discapacitadas; toda vez que se debe entender que los principios rectores de la política social y económica del Capítulo III del Título I de la Carta Magna pueden ponerse en conexión directa con la regla competencial ex art. 149.1.1 de la CE. Así, lo entendió el Tribunal Constitucional cuando afirmó que «las facultades normativas en materia de pensiones asistenciales aquí impugnadas encuentran claro apoyo competencial -como señala el Abogado del Estado- en el art. 149.1.1, en conexión con el art. 50 ambos de la Constitución, que habilitan al Estado para establecer normativamente los principios básicos que garanticen la igualdad en las posiciones jurídicas fundamentales de los españoles, en el presente caso, asegurando, con carácter general, una pensión asistencial mínima e idéntica para todos» (STC 13/1992, FJ 14). No obstante, no es menos cierto que para que unas ayudas estatales puedan fundamentarse en este título competencial, debe apreciarse en cada caso concreto la conexión directa de las mismas con la promoción de tal igualdad (STC 227/2012, de 29 de noviembre, FJ 5), lo cual exige un examen del objeto, el contenido o los beneficiarios de las ayudas. Precisamente, por esa falta de conexión, en una serie de sentencias recientes, el Tribunal Constitucional ha rechazado que el art. 149.1.1 de la CE sea un título competencial suficiente para justificar determinadas ayudas en materia de asistencia social (SSTC 173/2012, de 15 de octubre, FJ 5 a); 177/2012, de 15 de octubre, FJ 5 a), 21/2013, de 31 de enero, FJ 5; o 40/2013, de 14 de febrero, FJ 5).

A pesar de que la abundante conflictividad suscitada por las subvenciones estatales ha dado lugar a una muy completa y reiterada doctrina constitucional, el intérprete supremo de la Constitución ha tenido que pronunciarse de nuevo sobre este asunto, ya que la Generalitat de Cataluña promovió un conflicto positivo de competencia contra la resolución, de 18 de mayo de 2016, de la Secretaria de Estado de servicios sociales e igualdad, por la que se convocaban subvenciones estatales destinadas a la realización de programas de interés general con cargo a la asignación tributaria del impuesto sobre la renta de las personas físicas (en adelante, IRPF) por vulnerar las competencias de Cataluña en materia de asistencia social ${ }^{25}$.

aprobación de la Ley 27/2013, de 27 de diciembre, de racionalización y sostenibilidad de la Administración Local y la consiguiente introducción de modificaciones en la regulación de las competencias de los municipios en el campo de los servicios sociales, el Pleno del Tribunal Constitucional dictaminó, al resolver el recurso interpuesto por la Asamblea legislativa de Extremadura, la nulidad de la disposición transitoria segunda del texto legal por extralimitación competencial. Para conocer el alcance jurídico de las transformaciones del sistema competencial perseguidas por la Ley 27/2013, de 27 de diciembre, de racionalización y sostenibilidad de la Administración Local, nos remitimos a ALMEIDA CERREDA, Marcos: «El impacto de la Ley 27/2013, de 27 de diciembre, de racionalización y sostenibilidad de la administración local, en la distribución de competencias en materia de educación, salud, sanidad y servicios sociales», Revista d'estudis autonòmics i federals, núm. 22, 2015, págs. 219-263.

${ }^{25} \mathrm{El}$ art. 114 del Estatuto de Autonomía de Cataluña dispone: «1. Corresponde a la Generalitat, en las materias de su competencia, el ejercicio de la actividad de fomento. A tal fin, la Generalitat puede otorgar subvenciones con cargo a fondos propios.

2. Corresponde a la Generalitat, en las materias de competencia exclusiva, la especificación de los objetivos a los que se destinan las subvenciones estatales y comunitarias europeas territorializables así 
Al encontrarse en una situación de esta índole, el Tribunal Constitucional declara: «en estas circunstancias no cabe sino pensar que todo ello denota una escasa eficacia del sistema institucional de nuestro Estado y de la garantía de la supremacía de la Constitución Española». Cansado de la sucesión de conflictos de competencia suscitados por el mismo objeto, se recuerda: «en la STC 21/2013 ya hubimos de recordar lo que dijimos en la STC 208/1999, de 11 de noviembre (FJ 7), sobre la necesidad de que, para la plena realización del orden de competencias que se desprende de la Constitución y los Estatutos de Autonomía, se evite la persistencia de situaciones anómalas en las que sigan siendo ejercitadas por el Estado competencias que no le corresponden. Como entonces afirmamos, la lealtad constitucional obliga a todos (STC 209/1990, FJ 4) y comprende, sin duda, el respeto a las decisiones de este Alto Tribunal (FJ 8). Su cumplimiento pleno y tempestivo, al que vienen obligados todos los poderes públicos (art. 87.1 LOTC), exige que el Estado aborde sin demora la modificación del marco regulador de estas subvenciones, a fin de acomodarlo para futuras convocatorias a lo que resulta de la clara y excesivamente reiterada doctrina constitucional, en su dimensión tanto normativa como ejecutiva».

Desde la STC 13/1992, de 6 de febrero, hasta la actualidad, el Tribunal Constitucional ha dictado más de 70 sentencias. La lectura de la Sentencia núm. 9/2017, de 19 de enero, puede tener relevancia, al menos, desde dos puntos de vista. En primer lugar, en la medida que se explica que es erróneo argumentar que se está ante actuaciones propias de los ámbitos de la sanidad, la educación, la legislación laboral, y la seguridad pública, materias en las que los apartados 7, 13, 16, 29 y 30 del art. 149.1 de la CE han reservado competencias al Estado. Sin duda, la prestación de las actividades asistenciales causará a su vez unos efectos que contribuirán a la mejora de la situación sociosanitaria, educativa y laboral de los colectivos que las recibirán, e incluso pueden producir una mejora de la seguridad ciudadana y tendrán un efecto preventivo de la delincuencia. De todas formas, esas serán en todo caso las consecuencias finales e indirectas de la asistencia social prestada, por lo que los títulos competenciales invocados por el Estado no le habilitan a convocar y establecer gestión centralizada de las subvenciones, máxime cuando en dichas materias las funciones ejecutivas corresponden a la Generalitat en mérito a las previsiones estatutarias referidas a materia de sanidad y salud pública (art. 162 del EAC), educación (art. 131 del EAC), trabajo (art. 170 del EAC), seguridad pública (art. 164 del EAC), juventud (art. 142 del EAC) y políticas de género (art. 153 del EAC).

La Sentencia núm. 9/2017, de 19 de enero, ha tenido también la ocasión de pronunciarse inequívocamente sobre el dato relativo al posible ámbito territorial de actuación de la entidad beneficiaria de la ayuda. Según la jurisprudencia constitucional, la exigencia de

como la regulación de las condiciones de otorgamiento y la gestión, incluyendo la tramitación y la concesión.

3. Corresponde a la Generalitat, en las materias de competencia compartida, precisar normativamente los objetivos a los que se destinan las subvenciones estatales y comunitarias europeas territorializables, así como completar la regulación de las condiciones de otorgamiento y toda la gestión, incluyendo la tramitación y la concesión.

4. Corresponde a la Generalitat, en las materias de competencia ejecutiva, la gestión de las subvenciones estatales y comunitarias europeas territorializables, incluyendo la tramitación y la concesión.

5. La Generalitat participa en la determinación del carácter no territorializable de las subvenciones estatales y comunitarias europeas. Asimismo, participa, en los términos que fije el Estado, en su gestión y tramitación». 
que las entidades beneficiarias desarrollen proyectos de ámbito estatal no determina el órgano administrativo titular de la competencia material (STC 146/1986, FJ 6). La supraterritorialidad no es en sí misma un título competencial porque existen otros modelos distintos al de la actuación directa del Estado para diseñar una política de ayudas ( SSTC 178/2011, FJ 5, y 89/2012, FJ7) y el carácter supraautonómico de las ayudas no justifica la competencia estatal, ya que la persecución del interés general se ha de materializar a través de los sistemas de reparto de competencias articulados en la Constitución [ SSTC 77/2004 , FJ 6 b); 113/2013 , FJ 7; 150/2013 , FJ 6 a), y 163/2013, FJ 4). Ni la incidencia supraautonómica de las ayudas justifica la centralización de su tramitación y gestión, ni la adopción de un sistema de ayudas basado en la decisión unitaria del Estado con la consiguiente exclusión de la competencia autonómica por el mero hecho de la supraterritorialidad, resultan compatibles con la Constitución (SSTC 126/2002, FJ 9; 38/2012, FJ 5, y 89/2012, FJ 7). Por otra parte, la condición de que los programas subvencionables tengan alcance supraautonómico no es relevante para justificar la convocatoria y gestión centralizada de las ayudas, pues para que el sistema de ayudas sea incardinable en el supuesto al que se refiere la STC 13/1992, FJ.8 d), no basta con que los programas subvencionables sean de ámbito supraautonómico sino que resulta necesario probar, correspondiendo la carga al Estado, que no cabe su gestión fraccionada o mediante mecanismos de cooperación [ SSTC 38/2012 , FJ 7; 113/2013, FJ 7, y 144/2014 FJ 2 a)].

Procede sólo añadir que tampoco puede ser de aplicación el título competencial del Estado recogido en el art. 149.1.14 de la CE por más que el origen de los fondos que financian estas subvenciones esté relacionado con la asignación tributaria del IRPF para fines de interés general, del mismo modo que son absolutamente ajenos a este debate competencial la libertad religiosa (art. 16 de la CE) o los compromisos derivados de los acuerdos del Estado con la Santa Sede.

Teniendo en cuenta la jurisprudencia constitucional, pensamos que la validez de la Disposición transitoria única de la LTSAS y el art. 20.1 de la LV es discutible. La percepción de estos dos textos legales como normas cruciales para el fortalecimiento del tercer sector de acción social y el voluntariado no puede acallar las reivindicaciones de las Comunidades Autónomas en este campo. Asimismo, resulta reprochable, desde un punto de vista ético, que se indique que las medidas incluidas en estas Leyes «no podrán suponer un incremento del gasto público» (Disposición adicional cuarta de la LTSAS y Disposición final quinta de la LV). Es alarmante que la normativa, ni si quiera, declare que los gastos públicos se van a condicionar a la evolución general de la economía y a las disponibilidades presupuestarias.

\section{III.EL FOMENTO DEL TERCER SECTOR DE ACCIÓN SOCIAL Y DEL VOLUNTARIADO A PARTIR DE UNA REFORMA DE LA LEGISLACIÓN DE LA CONTRATACIÓN PÚBLICA}

Con el fin de promover los principios del tercer sector de acción social, garantizar su sostenibilidad y su participación en las políticas sociales, la LTSAS prevé la aprobación por el Gobierno, en el plazo de doce meses desde su entrada en vigor, de un programa de impulso, que contendrá diversas medidas, tales como la promoción, difusión y formación del tercer sector de acción social, su cooperación con los servicios públicos 
estatales, la financiación pública de estas entidades o la participación institucional ${ }^{26}$. En cuanto al voluntariado, cabe anotar que el nuevo régimen legal se completará con un reglamento, pues la Disposición final sexta de la LV habilita al Gobierno para que en el plazo de seis meses a partir de la entrada en vigor se apruebe un reglamento de ejecución.

Hay que añadir que no estamos de acuerdo con que la implementación de las medidas se supedite a la aprobación posterior de un programa o de un reglamento. No puede manifestarse que el tercer sector de acción social y el voluntariado desempeñan un papel crucial en el diseño y la ejecución de las políticas contra la pobreza y la exclusión social $\mathrm{y}$, a continuación, proporcionar un marco jurídico incompleto. Además, especulemos: ¿Qué sucedería si ese programa o reglamento se aprobara más tarde de lo estipulado o nunca se aprobara?, ¿respondería alguien ante el incumplimiento de las órdenes de ejercitar la potestad reglamentaria? Creemos que llegado el caso lo que pasaría sería que no sucedería nada y nadie respondería. De hecho, el plazo para el desarrollo reglamentario ya ha concluido y el 24 de enero de 2017 el diputado Carles Campuzano i Canadés presentaba al Gobierno las siguientes preguntas para respuestas escritas “¿En qué estado se encuentra el desarrollo reglamentario de la Ley de voluntariado y la Ley del Tercer Sector? y ¿Tiene previsto el Gobierno simplificar el régimen de subvenciones de las entidades del Tercer Sector? ${ }^{27}$

Llegados a este punto de la exposición, resulta pertinente remarcar que el Diario Oficial de la Unión Europea de 28 de marzo de 2014 publicaba el nuevo paquete legislativo comunitario sobre la contratación pública. En concreto, se trata de la Directiva 2014/24/UE relativa a la contratación pública, que deroga la Directiva 2004/18/CE; la Directiva 2014/25/UE relativa a la contratación por entidades que operan en los sectores del agua, la energía, los transportes y los servicios postales, que deroga la Directiva 2004/17/CE; y la novedosa Directiva 2014/23/UE relativa a la adjudicación de contratos de concesión. Tales normas comunitarias entraron en vigor a los veinte días de su publicación y establecen un período general de transposición que finaliza el 18 de abril de 2016, obligando al Estado español, al igual que a los restantes Estados miembros, a incorporar próximamente modificaciones en el Derecho interno.

Lograr una contratación socialmente más responsable es una de las claves de esta nueva etapa. Ello requiere incorporar en todos los procedimientos contractuales objetivos específicos de política social, como el fomento del empleo de personas en situación o en riesgo de exclusión social, la inserción social y laboral de personas con discapacidad física y/o intelectual, el diseño y accesibilidad para todos; la estabilidad y calidad en el empleo, la mejora de la seguridad y salud laboral, la promoción de la igualdad efectiva entre hombres y mujeres, la responsabilidad social de las empresas, las medidas de conciliación de la vida familiar y laboral, y criterios de comercio justo y compra pública ética.

En los últimos años, la integración de aspectos sociales y medio ambientales, la promoción de las PYMES y el impulso de la sostenibilidad en la contratación pública han sido objeto de análisis y regulación mediante instrumentos diversos, de carácter europeo, nacional, autonómico y local, y también son numerosos los dictámenes e

\footnotetext{
${ }^{26}$ Arts. 6 y 7.

${ }^{27}$ Boletín Oficial de las Cortes Generales, núm. 96, 31 de enero de 2017.
} 
informes que las distintas Juntas Consultivas de contratación administrativa y otros órganos consultivos han emitido sobre dichas cuestiones.

Ante la inminente revisión del Real Decreto Legislativo 3/2011, de 14 de noviembre, por el que se aprueba el texto refundido de la Ley de Contratos del Sector Público, y la innegable competencia del Estado para legislar en esta materia, estamos convencidos de que un debate que habría que retomar es el de la reserva de contratos relativos a prestaciones de carácter asistencial. El no sometimiento a concurrencia pública de un determinado contrato y la consiguiente reserva para cierto tipo de entidades, por ejemplo, aquellas que conforman el tercer sector de acción social o las entidades de voluntariado, sí que ayudaría al fortalecimiento de estas organizaciones y además no plantearía dudas en términos competenciales ${ }^{28}$.

Con independencia de que, tal y como señala la Directiva 2014/24/UE del Parlamento Europeo y del Consejo de 26 de febrero de 2014 sobre contratación pública, corresponde a los Estados miembros decidir cómo se organiza la prestación de los servicios sociales ${ }^{29}$, no puede obviarse que las instituciones comunitarias han admitido que ciertos servicios de este tipo tienen una dimensión transfronteriza limitada y, por tanto, estaría justificado un régimen específico para los contratos públicos relativos a tales servicios ${ }^{30}$. A la hora de configurar ese régimen específico, se explica que se establecerán normas nacionales para la adjudicación de los contratos que, por una parte, respeten los principios de transparencia y de igualdad de trato de los operadores económicos y que, por otra, tengan en cuenta la especificidad de los servicios ${ }^{31}$. También se anuncia que los Estados miembros velarán por que los poderes adjudicadores puedan tener en cuenta la necesidad de garantizar la calidad, la continuidad, la accesibilidad, la asequibilidad, la disponibilidad y la exhaustividad de los servicios, las necesidades específicas de las distintas categorías de usuarios, incluidos los grupos desfavorecidos y vulnerables, la implicación y la responsabilización de los usuarios y la innovación ${ }^{32}$. Además, se podrá reservar en algunos casos a determinadas organizaciones el derecho de participación en procedimientos de adjudicación de contratos públicos. En este sentido, el art. 77.2 de la Directiva 2014/24/UE establece que la duración del contrato no excederá de tres años y que las organizaciones deberán cumplir todas las condiciones siguientes:

a) que su objetivo sea la realización de una misión de servicio público vinculada a la prestación de los servicios contemplados en el apartado 1 del artículo 77.

b) que los beneficios se reinviertan con el fin de alcanzar el objetivo de la organización; en caso de que se distribuyan o redistribuyan beneficios, la distribución o redistribución deberá basarse en consideraciones de participación;

\footnotetext{
${ }^{28}$ Interesa puntualizar que la calificación de un contrato como reservado en ningún caso excluye otros requisitos y condiciones para ser admitido a una licitación, como la solvencia técnica, económica o profesional, la capacidad de obrar, la clasificación del contratista o el no hallarse incurso en prohibiciones para contratar. (Leire ÁLVAREZ DE EULATE BADA, "Guía para la aplicación de contratos reservados para empresas de inserción", 2015, disponible en http://www.gizatea.net/wp-content/uploads/Guiacontratos-reservados-EI cas.pdf)

${ }^{29}$ Considerando 6 .

${ }^{30}$ Considerando 114.

31 Art. 76.1.

${ }^{32}$ Art. 76.2.
} 
c) que las estructuras de dirección o propiedad de la organización que ejecute el contrato se basen en la propiedad de los empleados o en principios de participación o exijan la participación activa de los empleados, los usuarios o las partes interesadas, y

d) que el poder adjudicador de que se trate no haya adjudicado a la organización un contrato para los servicios en cuestión con arreglo al presente artículo en los tres años precedentes $^{33}$.

Tras un breve análisis de la Directiva 2014/24/UE y la Directiva 2014/23/UE, debe destacarse que en las dos normas se reconoce que las reglas contractuales no deben aplicarse a determinados servicios de emergencia prestados por organizaciones $\mathrm{o}$ asociaciones sin ánimo de lucro, ya que sería difícil preservar la especial naturaleza de estas organizaciones en el caso de que estos prestadores de servicios tuvieran que elegirse con arreglo a los procedimientos de contratación ${ }^{34}$. El Derecho de la Unión Europea reconoce las singularidades tanto de los servicios sociales como de las organizaciones o asociaciones sin ánimo de lucro. A partir de esa realidad, se acepta la construcción de un régimen particular de contratación y las reservas de contratos y concesiones. De todos modos, la última palabra en esta materia la tienen los Estados miembros y, en este sentido, el Proyecto de Ley de Contratos del Sector Público, por la que se transponen al ordenamiento jurídico español las mencionadas Directivas, no es muy alentador.

La despreocupación u olvido del Estado puede contemplarse como un modo de evitar recursos de inconstitucionalidad, pues las Comunidades Autónomas han asumido los servicios sociales como una competencia exclusiva y la aprobación de la LTSAS y la LV ha suscitado no pocas dudas desde el punto de vista competencial. Ahora bien, prescindiendo de las elucubraciones y teorías que puedan explicar que esta temática no esté reflejada en el citado Proyecto de Ley, importa notar que todos los grupos parlamentarios ${ }^{35}$ han presentado enmiendas con la intención de cambiar este hecho.

Con base a lo expuesto, se ha recordado que el Tribunal de Justicia de la Unión Europea se ha pronunciado de manera reiterada y unánime (Sentencia de 11 de diciembre de 2014, asunto C-113/13, decisión prejudicial, caso Spezzino; y Sentencia de 28 de enero de 2016, asunto C-50/14, decisión prejudicial, caso Casta) en el sentido de que no se consideran contrarios a la libertad de establecimiento y a la libre prestación de servicios (arts. 49 y 56 del TFUE) la adjudicación de contratos públicos (además de manera directa y sin publicidad) en favor de la Cruz Roja italiana, siempre que, como señala este Tribunal, la prestación de servicios contribuya realmente a una finalidad social no

\footnotetext{
${ }^{33}$ La novedosa Directiva 2014/23/UE relativa a la adjudicación de contratos de concesión prevé también las concesiones reservadas. En concreto, el art. 24 señala: "los Estados miembros podrán reservar la participación en los procedimientos de adjudicación de concesiones a talleres protegidos y operadores económicos cuyo objetivo principal sea la integración social y profesional de personas discapacitadas o desfavorecidas, así como prever la ejecución de las concesiones en el contexto de programas de empleo protegido, siempre que al menos el $30 \%$ de los empleados de tales talleres, operadores económicos o programas sean trabajadores discapacitados o desfavorecidos. En el anuncio de las concesiones o, en caso de las concesiones de servicios definidas en el artículo 19, en un anuncio de información previa deberá mencionarse el presente artículo".

${ }^{34}$ Considerando 28 de la Directiva 2014/24/UE y Considerando 36 de la Directiva 2014/23/UE.

${ }^{35}$ Grupo Parlamentario Socialista, Grupo Parlamentario Confederal de Unidos Podemos-En Comú Podem En Marea, Grupo Parlamentario Ciudadanos, Grupo Parlamentario de Esquerra Republicana, Grupo Parlamentario Vasco y Grupo Parlamentario Mixto.
} 
lucrativa y a la consecución de los objetivos de solidaridad y de eficiencia presupuestaria. La jurisprudencia comunitaria ha sido asumida por el Informe 17/2008, de 21 de julio, de la Junta Consultiva de Contratación Administrativa de Aragón y por las Comunidades Autónomas, si bien en esta línea sería conveniente establecer sistemas homogéneos a nivel nacional, ya que lo contrario supondría diseñar sistemas de adjudicación de servicios sociales de forma muy dispar ${ }^{36}$.

Provoca cierta perplejidad que el Proyecto de Ley de Contratos del Sector Público siga manteniendo la regulación de los contratos reservados oculta en una disposición adicional, la cuarta, lo que provoca que muchos servicios jurídicos, secretarios o interventoras, así como técnicos de contratación desconozcan por completo esta posibilidad ${ }^{37}$. En coherencia con lo anterior, se defiende que la reserva para entidades de economía social y no lucrativa en el caso de los contratos de servicios sociales figure en el propio articulado. No obstante, se indica que mientras no llegue ese momento la regulación de los contratos reservados de importe inferior a 750.000 euros es obligatoria, ya que las Directivas son de aplicación directa finalizado su plazo de transposición ${ }^{38}$.

La economía social supone en España el 10\% del PIB y el 12,5\% del empleo con 2,2 millones de puestos de trabajo directos e indirectos. Se trata de empresas de todos los tamaños, que operan en la totalidad de sectores y que adoptan formas jurídicas de cooperativas, sociedades laborales, mutualidades, empresas de inserción, centros especiales de empleo, cofradías de pescadores, federaciones, fundaciones y asociaciones. Se ha demostrado que la economía social ha resistido mucho mejor los embates de la crisis económica que las empresas mercantiles convencionales. El estudio de FUNCAS denominado «Tercer sector», atribuye a la economía social el carácter de «contra-cíclico y anticrisis», pues de 2003 a 2010 mientras no dejaba de subir el paro, el empleo remunerado en este sector se incrementó en un 26,8\% en toda Europa. En España se ha constatado también que en épocas de recesiones económicas la destrucción de empleo en el sector de la economía social ha sido notoriamente inferior y la creación de empleo se inicia antes que en la economía convencional. Sin embargo, el análisis de la relación entre la economía social y la contratación pública ofrece unos datos alarmantes según un estudio realizado por el Instituto de Derecho Cooperativo y Economía Social (GEZKI), de la Universidad del País Vasco. En este trabajo de investigación se extrae la conclusión de que la economía social había resultado adjudicataria del 1,90\% de los importes totales de los contratos públicos en 2010-2012,

\footnotetext{
${ }^{36}$ Véanse las enmiendas núm. 907 y núm. 1.042.

${ }^{37}$ Véanse las enmiendas núm. 25, núm. 284 y núm. 286.

${ }^{38}$ Sobre los efectos jurídicos de la falta de transposición en plazo de las Directivas de contratación pública, conviene reseñar la Resolución de 16 de marzo de 2016, de la Dirección General del Patrimonio del Estado, por la que se publica la Recomendación de la Junta Consultiva de Contratación Administrativa, sobre el efecto directo de las nuevas Directivas comunitarias en materia de contratación pública (BOE núm. 66 de 17 de marzo de 2016). Asimismo, conviene indicar que se contienen también instrucciones en el Informe 17/2015, de 3 de diciembre, de la Junta Consultiva de Contratación Administrativa de la Comunidad Autónoma de Aragón, relativo a los «Efectos de las Directivas de contratación pública en la regulación de la Ley 3/2011, de 24 de febrero, de medidas en materia de Contratos del Sector Público de Aragón, tras la conclusión del plazo de transposición. Posibilidades de desarrollo» y en el Informe 1/2016, de 6 de abril, de la Junta Consultiva de Contratación Administrativa de la Generalitat de Catalunya, relativa a «Contenidos de la Directiva 2014/24/UE, de 26 de febrero de 2014, sobre contratación pública, que tienen que ser de aplicación directa a partir del día 18 de abril de 2016, fecha en que finaliza el plazo para su transposición. Breve referencia a la aplicación directa de la Directiva 2014/23/UE, de 26 de febrero de 2014, relativa a la adjudicación de contratos de concesión».
} 
y del 2,40\% en el periodo 2011-2013. Por tanto, la economía social se encuentra infrarrepresentada en la adjudicación de contratos públicos y el porcentaje de contratos públicos adjudicados a entidades de economía social resulta irrisoria en relación con su peso real en el PIB y en la creación de empleo ${ }^{39}$. En último lugar, merece remarcarse que la Resolución, de 10 de septiembre de 2015, del Parlamento Europeo sobre emprendimiento social e innovación social en la lucha contra el desempleo (2014/2236(INI)) se refiere de manera expresa a la exigencia y necesidad de promover la reserva de contratos a las entidades de economía social y solidaria, exigiendo a los Estados miembros la transposición efectiva e inmediata de las Directivas comunitarias de contratos públicos y lamentando las trabas en el acceso a la contratación pública de estos sujetos.

Finalmente, cabe anotar que una parte importante de los recursos por vía pública que reciben el tercer sector de acción social y el voluntariado llegan a través de subvenciones. A estos efectos, conviene puntualizar lo siguiente: «consideraremos incluida en la esfera de la competencia estatal la regulación de los aspectos centrales del régimen subvencional -objeto y finalidad de las ayudas, modalidad técnica de las mismas, beneficiarios y requisitos esenciales de acceso- mientras que situaremos dentro de la competencia autonómica lo atinente a su gestión, esto es, la tramitación, resolución y pago de las subvenciones, así como la regulación del procedimiento correspondiente a todos estos aspectos», ya que es doctrina reiterada del Tribunal Constitucional que «las normas procedimentales ratione materiae deben ser dictadas por las Comunidades Autónomas competentes en el correspondiente sector material, respetando las reglas del procedimiento administrativo común» (STC 36/2012, de 15 de marzo, FJ 8; doctrina aplicada posteriormente en las SSTC 72/2012, de 16 de abril, FJ 4; 73/2012, de 16 de abril, FJ 4; 77/2012, de 16 de abril, FJ 4; 173/2012, de 15 de octubre, FJ 7; 177/2012, de 15 de octubre, FJ 7; 226/2012, de 29 de noviembre, FJ 3; 227/2012 de 29 de noviembre, FJ 5; 21/2013, de 31 de enero, FJ 6, 40/2013, de 14 de febrero, FJ 6, o 70/2013, de 14 de marzo, FJ 6).

En un Dossier titulado «Hacia un nuevo modelo de financiación del Tercer Sector» se detallan las dificultades burocráticas con las que estas organizaciones se encuentran, las cuales anunciamos inmediatamente.

- La justificación de las subvenciones incrementa los gastos administrativos.

- La ley no prevé poder incluir como norma habitual partidas de gastos corrientes ni de funcionamiento ordinario.

- En los casos de cofinanciación de la actividad no se prevé la posibilidad de hacer una justificación única.

- Cuando parte de la actividad se financia con recursos propios, se exige la justificación de la totalidad de la actividad con facturas originales.

- El mecanismo de subvenciones anuales no permite mantener el desarrollo de las actividades de manera continuada.

- No incluye la obligatoriedad de establecer plazos de pago ni tampoco prevé el pago anticipado.

- El régimen de sanciones e infracciones administrativas es inadecuado y, en ocasiones, desproporcionado.

${ }^{39}$ Véase enmienda núm. 286 
Ante el panorama descrito, la Taula del Tercer Sector presentó un documento «Propuestas para la mejora de los procedimientos de adjudicación de subvenciones de las Administraciones Públicas en el ámbito de la atención a las personas». Las propuestas son las siguientes:

- Justificación sólo del importe subvencionado y aportación de una declaración responsable por el importe no subvencionado.

- Pago de todo el importe de la subvención al inicio del proyecto.

- Fijación en las bases de plazos de pago y aceptación de los costes financieros (cuando la entidad tenga que avanzar parte o la totalidad del importe de la subvención) entre los gastos subvencionados.

- Aceptación de un mínimo del $10 \%$ de gastos indirectos (gastos corrientes, de personal y de funcionamiento ordinario) y que no haya que justificarlos.

- Importe de la subvención que cubra como mínimo el $80 \%$ del presupuesto del proyecto.

- Convocar subvenciones plurianuales para las actividades y servicios con continuidad.

- Convocatoria como máximo en febrero y resolución como máximo en abril para las subvenciones (plurianuales o anuales) destinadas a servicios a las personas y que afectan a estructuras de personal.

- Simplificación de los procesos en una misma Administración homogeneizando los criterios de las convocatorias, integrando en una única convocatoria todas las subvenciones relacionadas con los servicios a las personas y creando un sistema centralizado de identificación, ayuda y gestión de subvenciones.

- Incorporación de todos los requisitos en las bases de las convocatorias.

- Justificación económica mediante auditoría o bien una relación de facturas, sin exigencia de presentar facturas originales o copias.

- Permitir que una parte de la cofinanciación del proyecto sea en especies (cesión de locales, colaboraciones de personal...) de acuerdo con su valor de mercado.

- Incrementar las subvenciones de concesión directa.

Como colofón, estimamos pertinente subrayar que muchas de las necesidades del tercer sector de acción social y del voluntariado podrían satisfacerse sin la modificación de la Ley 38/2003, de 17 de noviembre, General de Subvenciones. Ello se demuestra, a título ejemplificativo, en la Disposición adicional séptima de la LTSAS, en la cual se insta a que «en atención al interés general al que sirven y a las singularidades de su naturaleza y actividades, dentro del marco general de la normativa sobre subvenciones, las bases reguladoras de las convocatorias de la Administración General del Estado contemplarán las especialidades de las entidades del Tercer Sector de Acción Social en materia de apoyos, ayudas y subvenciones públicas».

\section{CONCLUSIONES}

Debido a que el Estado no ha invocado un título competencial suficiente sobre la materia objeto de análisis, discutimos, en primer lugar, la validez constitucional de los dos textos legales examinados en el presente estudio. A nuestro juicio, el legislador estatal no pretende promocionar las estructuras organizativas sin ánimo de lucro porque 
sí, sino que su intención es impulsar las actuaciones de protección a las situaciones de necesidad que se producen en la sociedad y que dichas organizaciones llevan a cabo. Puesto que la Comunidad Autónoma ostenta una competencia exclusiva sobre asistencia social, consideramos que la forma de proceder del legislador estatal es poco acorde y respetuosa con la autonomía que la Constitución reconoce a las Comunidades Autónomas.

Para terminar, es preciso subrayar que la seguridad jurídica exige aprobar normas de claro contenido. Pues bien, debe hacerse hincapié en que las definiciones del tercer sector de acción social, el voluntariado y las entidades de voluntariado son mejorables. Asimismo, tampoco nos parece acertado que las expresiones tercer sector, tercer sector social y tercer sector de la acción social se utilicen de manera indistinta. Tomando como supuesto de base que una de las maneras de determinar si hay una adecuada ejecución de las políticas públicas es evaluar el cumplimiento eficaz de las leyes, constatamos que, a día de hoy, las órdenes de desarrollo reglamentario previstas en la LTSAS y la LV no se han ejecutado. Sea como fuere, cualquier mandato, medida o declaración recogida en esta nueva normativa es difícilmente realizable cuando, al mismo tiempo, se rechaza un incremento del gasto público. En último lugar, importa destacar que lo que está fuera de toda duda es que otra regulación de la contratación pública en España es posible. El Parlamento europeo ha admitido las dificultades de las organizaciones sin ánimo de lucro a la hora de participar en procedimientos de contratación y el tratamiento de los servicios sociales que se realiza en las Directivas es más rupturista e innovador que el que pretende efectuar el legislador español. Llegados a este punto, planteamos la utilidad de, en primer término, reformar el marco normativo aplicable a la contratación pública teniendo en cuenta las enmiendas presentadas por los grupos parlamentarios al Proyecto de Ley de Contratos del Sector Público y, en segundo lugar, someter a un nuevo examen los procedimientos de adjudicación de subvenciones con el objeto de que el acceso a la financiación sea más fácil para el tercer sector.

\section{BIBLIOGRAFÍA}

ALMEIDA CERREDA, Marcos: «El impacto de la Ley 27/2013, de 27 de diciembre, de racionalización y sostenibilidad de la administración local, en la distribución de competencias en materia de educación, salud, sanidad y servicios sociales», Revista d'estudis autonòmics i federals, núm. 22, 2015, págs. 219-263.

ÁLVAREZ DE EULATE BADA, Leire: "Guía para la aplicación de contratos reservados para empresas de inserción”, 2015, disponible en http://www.gizatea.net/wpcontent/uploads/Guia-contratos-reservados-EI_cas.pdf

Anuario del Tercer Sector de Acción Social en España, Fundación Luis Vives, Madrid, 2012.

IZQUIETA ETULIAN, José Luis: Voluntariado y tercer sector. Cultura, participación cívica y organizaciones solidarias, Tecnos, Madrid, 2011.

LORENZO GARCÍA, Rafael: "Las claves del Tercer Sector: análisis y realidad actual", Nuevo Tratado de Fundaciones, Rafael de LORENZO GARCÍA, José Luis PIÑAR MAÑAS y Isabel PEÑALOSA ESTEBAN (dirs.), Aranzadi, Madrid, págs. 1001-1037. 
MUÑOZ MACHADO, Santiago: "La contribución de las organizaciones sociales a la transformación del Estado de Bienestar", Las estructuras del bienestar. Propuestas de reformas y nuevos horizontes, Civitas, Madrid, 2002.

PÉREZ ESCOLAR, Marta y VALERO MATAS, Jesús Alberto: Entes sin ánimo de lucro. Fundamentos sociológicos. (Manual teórico-práctico adaptado EEES), Tecnos, Madrid, 2013.

PIÑAR MAÑAS, José Luis: "El estado actual del modelo constitucional de fundaciones: revisión crítica", Nuevo Tratado de Fundaciones, Rafael de LORENZO GARCÍA, José Luis PIÑAR MAÑAS y Isabel PEÑALOSA ESTEBAN (dirs.), Aranzadi, Madrid, págs.55-104.

RODRÍGUEZ-ARANA MUÑOZ, Xaime: "El interés general en el Derecho Administrativo: notas introductorias", Revista Jurídica de Canarias, núm. 24, 2012, págs. 41-54.

TORNOS MAS, Joaquín: "Significación y consecuencias jurídicas de la consideración de los servicios sociales como servicio público", Cuadernos de Derecho Local, núm. 6, 2004, págs. 7-18.

VAQUER CABALLERÍA, Marcos: "Las relaciones entre Administración pública y tercer sector, a propósito de la asistencia social en Italia”, Revista de Administración Pública, núm. 152, mayo-agosto 2000, http.//revistaonline.inap.es.

*La autora es miembro del Grupo de potencial crecimiento "Empresa y Administración" (ED431B-2016) y Red "Empresa y Administración" (ED431D 2017/19), financiados por el Programa de Consolidación y Estructuración de Unidades de Investigación Competitivas de la Xunta de Galicia. 